\title{
midiätica@)
}

\section{Em nome do neoliberalismo: os editoriais de "jornais de referência" ao final do primeiro ano da gestão Temer}

\author{
In the name of neoliberalism: the editorials of "reference newspapers" at the end of \\ the first year of the Temer government
}

Carlos Alberto ZANOTTI ${ }^{1}$

\begin{abstract}
Resumo
Este trabalho adota a perspectiva da Análise Crítica de Discurso (ACD) para compreender a ideologia subjacente aos editoriais de dois "jornais de referência", sediados na capital do principal Estado do país, por ocasião das comemorações do primeiro ano do mandato de Michel Temer à frente da Presidência da República. Para tanto, além de cumprir os passos preconizados pela ACD, introduzimos a elaboração de quadros discursivos, com o intuito de tornar o menos subjetivo possível o resultado da análise. O trabalho parte de uma exposição sobre o papel do sistema de mídia, discute a função dos jornais e observa os editoriais como importante gênero discursivo de produção simbólica. O resultado aponta para a prática de "abuso de poder" (VAN DJIK, 2015) por parte das publicações, uma vez que seus discursos contribuem para com a manutenção de uma ordem social flagrantemente desigual.
\end{abstract}

Palavras-chave: Sociedade midiatizada. Editoriais. Análise Crítica de Discurso. Injustiça social.

\begin{abstract}
This work adopts the analytic perspective of Critical Discourse Analysis (CDA) to understand the ideology underlying the editorials of two "reference journals" based in the capital of the main Brazilian state. The texts were published on the occasion of the commemorations of the first year of the mandate of Michel Temer at the head of the Republic Presidency. For the purposes proposed here, in addition to complying with the steps recommended by the CDA, we introduced discursive frameworks with the intention of making the result of the findings the least subjective possible. The paper starts from showing on the role of the media system, discusses the role of newspapers, and views the editorials as an important discursive genre of symbolic production. The result points to the practice of "abuse of power" by publications, since their speeches contribute to the maintenance of a flagrantly unfair and unequal social order.
\end{abstract}

Keywords: Mediatized Society, Editorials, Critical Discourse Analysis, Social injustice.

\footnotetext{
${ }^{1}$ Doutor pela Escola de Comunicação e Artes da Universidade de São Paulo (USP). Professor da Faculdade de Jornalismo e do Programa de Pós-Graduação em Linguagens, Mídia e Arte, da PUCCampinas. Líder do grupo de pesquisa Sociedade Mediatizada: Processos, Tenologias e Linguagem. Email: zanotti@puc-campinas.edu.br
}

Ano X, n. 19 - jul-dez/2017 - ISSN 1983-5930 - http://periodicos.ufpb.br/ojs2/index.php/cm 


\section{midiática@e}

\section{Introdução}

O objetivo deste trabalho é contribuir, mesmo que de forma pontual, para com o debate acerca das relações que os chamados "jornais de referência" mantêm com os poderes político e econômico no Brasil contemporâneo, período marcado por uma persistente crise governamental que se arrasta desde as manifestações de junho de 2013. Para tanto, elegemos como objeto de estudo os dois principais jornais paulistas, Folha de S. Paulo e $O$ Estado de S. Paulo, que somam tiragem superior a $500 \mathrm{mil}$ exemplares/dia. O corpus submetido a análise são os editoriais por eles publicados ao término do primeiro ano da gestão de Michel Temer à frente do Executivo, aos quais aplicamos a Análise Crítica de Discurso (ACD) como perspectiva teórica.

Ao adotar o percurso metodológico inerente à $\mathrm{ACD}$, tínhamos claro que os estudos sobre a semiose -as formas de construção de sentidos- se inserem nas reflexões críticas a respeito do processo social, conforme pontua Fairclough (2012b, p. 308). Entre as principais formas de construção de sentido, encontram-se os discursos, entendidos como "maneiras semióticas de interpretar aspectos do mundo (físico, social ou mental) que geralmente podem ser identificados com diferentes posições ou perspectivas de diferentes grupos ou atores sociais" (FAIRCLOUGH, 2012a, p. 11). Interessou-nos compreender de que maneira o setor de imprensa representado por aquelas publicações avaliou o desfecho, ainda que parcial, da troca de governantes apoiada por elas no ano anterior. Para tanto, estruturamos este trabalho em quatro momentos. Primeiro, discutindo o papel dos jornais no sistema social; em seguida, o gênero compreendido pelos editoriais; depois, a pertinência da abordagem proposta pela ACD; e por fim, a análise propriamente dita, focando mais a comunicação que a gramática, como recomenda Wang (2016).

Antes de tudo, é preciso registrar que, ao mirar os jornais impressos, partimos do princípio de que são eles os mais típicos representantes do sistema de mídia informativa no postulado de Niklás Luhmann (2005), sociólogo que "elegeu a comunicação como operador central de todos os sistemas sociais” (MARCONDES FILHO, 2005, p. 7). Luhmann considera que o sistema dos meios de comunicação possui três diferentes modalidades de conteúdos: o jornalismo (notícias e reportagens), a publicidade e o 


\section{midiäticales}

entretenimento. Por essa perspectiva, entendemos que, de todos os meios, os jornais impressos são o único que existe exclusivamente em função do jornalismo, desempenhando a um só tempo os papéis de continente e conteúdo (ZANOTTI, 2016).

Registre-se ainda que não compartilhamos a hipótese de que focar os jornais impressos, neste período marcado pela crise em seu modelo de negócios e pelo surgimento de novas mídias (MEYER, 2007; MÜLLER, 2011), implique em anacronismos. Entendemos que o conceito de jornal está mais ligado ao papel que o meio desempenha, independentemente da plataforma onde estabelecem os contratos de leitura com seus públicos. Cabe ainda, como justificativa para a escolha, registrar que os jornais impressos -e certamente suas plataformas virtuais- continuam sendo, ao menos no caso brasileiro, os veículos de informação avaliados como sendo os mais confiáveis (BRASIL, 2016).

O grau de confiabilidade dos meios é determinante no processo de elaboração discursiva fomentado pelas mensagens da mídia. Elaboração discursiva pode ser compreendida como um movimento que, inicialmente, atinge o receptor primário, após o que as mensagens adquirem uma "audiência adicional de receptores secundários" (THOMPSON, 1998, p. 100) e vão alimentar o debate público.

Ao produzir e fazer circular informações, os jornais -uma "invenção fundamental do século XIX” (FOUCAULT, 1979, p. 224)- agem enquanto operadores privilegiados das relações de poder e da organização dos conflitos que perpassam o meio social. Seriam eles, como sugere Chaparro (2014, p. 38), um "espaço público dos confrontos discursivos", ou uma arena onde são travadas as batalhas pela conquista e manutenção do poder. Poder é aqui entendido como "a capacidade de intervir no curso dos acontecimentos e em suas consequências" (THOMPSON, 1998, p. 21). Capacidade esta que também se expressa em seu "abuso", qualificador que os estudos críticos do discurso apontam como sendo "as formas de dominação que resultam em desigualdade e injustiça sociais" (VAN DJIK, 2015, p. 10).

Entendemos ainda que os jornais não são um mero observador das disputas em torno do controle social. Eles próprios são uma forma de exercício de poder. Segundo Thompson, há quatro tipos de poder: econômico, político, coercitivo e simbólico, que frequentemente se sobrepõem. Os meios de comunicação e informação (ao lado de instituições como escolas, igrejas, universidades...) estariam inclinados ao exercício do 


\section{midiätica@e}

quarto tipo de poder, "cultural ou simbólico", pois "nasce da atividade de produção, transmissão e recepção do significado das formas simbólicas” (THOMPSON, 1998, p. 24).

Sendo assim, a atividade de produção simbólica por parte das mídias jornalísticas se encontra em pé de igualdade com as outras formas de exercício de poder. E ao exercê-lo, os meios de comunicação "interferem na atividade dos governos, marcam a agenda, colocando os políticos sob pressão constante e obrigando-os a tratar com urgência determinadas questões que requerem aprofundamento e estudo" (SERRANO, 1999, p. 10). Foi o que aconteceu com o episódio aqui observado, caracterizado por uma intensa negociação permeada pela mídia.

\section{Editoriais no jornalismo impresso}

Ao estudar gêneros e categorias no jornalismo, Melo (1994) inclui os editoriais entre as formas textuais do gênero opinativo. Diferentemente do que ocorre com notícias ou reportagens -que pertencem ao gênero informativo-, nos editoriais encontramos o discurso em seu "estado puro", ou seja, uma representação sem acontecimento (SILVA, 2007, p. 51). O editorial é um gênero quase que exclusivo da imprensa escrita, embora também apareça no rádio e na televisão, geralmente "em momentos de crise, de conturbação social, quando as emissoras se sentem compelidas a dizer o que pensam sobre os acontecimentos" (MELO, 1994, p. 104). A opinião do veículo representa o posicionamento dos grupos de interesse que gravitam em torno da publicação, como acionistas, anunciantes e um contingente de leitores.

Durante boa parte do século XIX, os editoriais foram chamados de artigos de fundo - textos opinativos originados no proprietário do jornal, responsável por representar os interesses de grupos políticos que exerciam o poder. Em tempos modernos, o editorial sofreu influência do modelo norte-americano, sendo hoje descrito como "um ensaio curto embebido em senso de oportunidade" (BOND, apud MELO, 2003, p.107). Segundo Moura (2012), a fórmula dos editoriais implica em linguagem impessoal, concisão nos argumentos, refutação de opiniões contrárias e conclusão que enfatiza o ponto de vista da empresa. 


\section{midiätica@e}

De um modo geral os editoriais se dirigem à coletividade ou ao Estado. São normalmente redigidos por profissionais identificados com a linha da publicação, embora não contenham assinatura de autoria. Nos jornais observados, eles contam com chamadas na primeira página e localizam-se nas páginas iniciais. Em seu manual de redação, $O$ Estado de S. Paulo nada explicita acerca dos editoriais, informando apenas que seus repórteres não devem opinar nos textos, o que ficaria a cargo dos editorialistas. A Folha de S. Paulo, em seu manual, reserva um verbete aos editoriais, recomendando que eles devam "[...] apresentar com concisão a questão de que se vai tratar, desenvolver os argumentos que o jornal defende, refutar as opiniões opostas e concluir condensando a posição adotada pela Folha.” (FOLHA DE S. PAULO, 1992, p. 70-71)

\section{Jornalismo de referência}

Os jornais observados nesta pesquisa circulam há praticamente um século, com tiragem diária total da ordem de meio milhão de exemplares, já bem adaptados à internet (SILVA, 2004). A Folha de S. Paulo, que surgiu em 1921, é hoje o diário de maior tiragem do país, enquanto O Estado de S. Paulo, fundado em 1875, ocupa o quarto lugar no ranking brasileiro; o primeiro possui tiragem de 304 mil exemplares; e o segundo, 210 mil (SACCHITIELLO, 2016).

Fiel às suas origens, o Estadão é considerado mais tradicional e conservador que seu concorrente. Fruto da associação de empresários republicanos, nasceu com o objetivo de combater a monarquia. A Folha, por outro lado, pertenceu a vários empreendedores do ramo, tendo dado apoio logístico ao golpe de Estado de 1964 (KUSHNIR, 2014). Seu slogan mais conhecido -“de rabo preso com o leitor”- dá uma clara ideia da linguagem menos formal que imprime aos seus conteúdos quando comparada ao concorrente.

Os dois matutinos paulistas estão entre aqueles que poderiam ser chamados de “jornais de referência", pois servem de modelo, fonte de informação e parâmetro de qualidade para outros jornais. A expressão jornalismo de referência opõe-se a “jornalismo popular”, este mais associado à dramatização. Entende-se como imprensa de referência a "instituição social que [...] age em nome de uma opinião pública interessada em observar o poder político e o exercício da democracia.” Relaciona-se 


\title{
midiäticales
}

com um sistema social mais amplo $\multimap$ das instituições políticas, econômicas, civis, educacionais, religiosas, etc.-, ao mesmo tempo em que o integra e conforma. Os meios de comunicação "de referência" são instituições que colocam em circulação elementos simbólicos a partir do vínculo e interação que estabelecem com o sistema social. (ZAMIN, 2014, p. 934).

\section{Discurso em análise crítica}

Para que pudéssemos compreender como se posicionaram os dois principais jornais paulistas por ocasião do primeiro ano da gestão de Michel Temer, elegemos como objeto de análise os editoriais Um ano de governo Temer ${ }^{2}$ (UM ANO, 2017), publicado em 12 de maio em $O$ Estado de S.Paulo; e O balanço de Temer $^{3}$ (O BALANÇO, 2017), publicado em 14 do mesmo mês na Folha de S.Paulo. Mais que tão somente elucidar o que disseram, interessou-nos lançar um olhar crítico sobre o corpus avaliado. Para tanto, recorremos às estratégias analíticas inerentes à Análise Crítica de Discurso, linha de trabalho inspirada na obra do linguista britânico Norman Fairclough, que esclarece:

\begin{abstract}
A Análise Crítica de Discurso (ACD) traz a tradição da análise crítica social para os estudos da linguagem e contribui para a análise social com foco particular no discurso e nas relações entre discurso e outros elementos sociais (relações de poder, ideologias, instituições, identidades sociais etc.). A análise crítica social pode ser entendida como uma crítica normativa e explicativa. ${ }^{4}$ (FAIRCLOUGH, 2012a, p. 9).
\end{abstract}

Ao aprofundar o que entende por crítica normativa, o autor explica que o compromisso da ACD não apenas descreve as realidades, mas observa até que ponto valores como justiça, decência e bem-estar social ali estão presentes. Já a crítica explicativa ocorre à medida que as mazelas encontradas, a exemplo de carências na área da saúde ou privação de bens materiais, podem ser associadas aos mecanismos e forças

\footnotetext{
${ }^{2}$ Disponível em: http://opiniao.estadao.com.br/noticias/geral,um-ano-do-governo-temer,70001775279

${ }^{3}$ Disponível em: http://www1.folha.uol.com.br/opiniao/2017/05/1883816-o-balanco-de-temer.shtml

${ }^{4}$ Tradução livre do autor para: "Critical discourse analysis (CDA) brings the critical tradition of social analysis into language studies and contributes to critical social analysis a particular focus on discourse and relations between discourse and other social elements (power relations, ideologies, institutions, social identities, and so forth). Critical social analysis can be understood as normative and explanatory critique."
} 


\section{midiäticales}

que movem o sistema capitalista. Ao discutir o método, as autoras brasileiras Resende e Ramalho (2014), que adotam a terminologia Análise de Discurso Crítica (ADC), explicam:

Trata-se de uma proposta que, com amplo escopo de aplicação, constitui modelo teórico-metodológico aberto ao tratamento de diversas práticas na vida social, capaz de mapear relações entre os recursos linguísticos utilizados por atores sociais e grupos de atores sociais e aspectos da rede de praticas em que a interação discursiva se insere. Os conceitos centrais da disciplina são de discurso e prática social." (RESENDE; RAMALHO, 2014, p. 11-12, com grifo das autoras)

Fairclough defende que a ACD é muito mais uma teoria que um método. Prefere descrevê-la como "uma perspectiva teórica sobre a língua" (2012b, p. 307-308) enquanto elemento (ou momento) do processo social material que dá margem a análises linguísticas ou semióticas inseridas em reflexões mais amplas sobre o processo social. A ACD parte, assim, de uma visão global do momento social -na atualidade, o neoliberalismo e a globalização- para observar como as relações de poder são atravessadas por estes movimentos. Ou seja, avalia de que modo a semiose leva à produção de gêneros discursivos, entendidos aqui como "maneiras diversas de agir, de produzir a vida social semioticamente." (FAIRCLOUGH, 2012b, p. 310).

Segundo Fairclough (2012b), a ACD se desenvolve ao longo de quatro passos, que exigem: 1) Dar ênfase no problema social que tenha um aspecto semiótico; 2) Identificar os obstáculos à resolução do problema; 3) Avaliar se o problema encontrado é inerente à ordem social; e 4) Identificar possíveis maneiras para a superação do problema. Em outro de seus textos, o autor acrescenta uma quinta etapa, que seria uma reflexão crítica sobre a própria análise desenvolvida pelo pesquisador.

Não pretendemos produzir uma análise exaustiva neste trabalho, mesmo porque não é este nosso principal objetivo. Para maior clareza do percurso adotado, focaremos quatro eixos temáticos para os quais buscamos os argumentos adotados nos editoriais, visando compreender: 1) Como Michel Temer é descrito no exercício do cargo; 2) Como os jornais avaliam seu desempenho; 3) O que os jornais consideram que deva ser sua principal tarefa à frente do cargo; e 4) Em nome de quem falam as publicações. Neste último, observaremos a existência ou não de recursos linguísticos que possam configurar o chamado discurso manipulador. Esta tipologia discursiva é inerente ao 


\section{midiätica@e}

"abuso de poder" - estratégia observada nos momentos em que os discursos proferidos legitimam situações de flagrante desigualdade social. "O discurso manipulador ocorre tipicamente na comunicação pública controlada pela elite política, burocrática, jornalística, acadêmica e empresarial dominante" (VAN DJIK, 2015, p. 251).

\section{Em nome do neoliberalismo}

Vale lembrar que os editoriais selecionados avaliam o primeiro ano de um governante que chegou ao cargo depois de a então presidente Dilma Rousseff (PT) ter sido afastada, pelo Congresso Nacional, em um movimento que a base aliada da exgovernante classificou de golpe parlamentar. Em função do impeachment, Michel Temer (PMDB), vice-presidente pela coligação partidária que a elegeu (e que abertamente conspirou contra ela), assumiu o poder. Por ocasião dos editoriais publicados, seu governo contava com apenas 7\% de aprovação dos eleitores brasileiros (BILENKY, 2017).

Em $O$ Estado de S. Paulo (Oesp), com 4.220 caracteres, o editorial teve por título Um ano do governo Temer, enquanto que na Folha de S.Paulo (FSP), com 2.720 caracteres, se chamou $O$ balanço de Temer. Neste caso, fazia uma clara alusão à insegurança do vice no exercício da governança, uma vez que estava envolvido em denúncias de corrupção, segundo apurou a Procuradoria Geral da República. Passemos aos excertos discursivos:

Quadro 1: Como Temer é descrito no exercício do cargo

\begin{tabular}{|l|l|}
\hline OESP & $\begin{array}{l}\text { Presidente Temer [...] marcado pela determinação de realizar } \\
\text { reformas }\end{array}$ \\
\cline { 2 - 3 } & $\begin{array}{l}\text { habilidoso para construir [...] maioria suficiente para aprovar } \\
\text { urgentes mudanças constitucionais }\end{array}$ \\
\cline { 2 - 3 } & muito malvisto pela opinião pública \\
\hline FSP & {$[$ ocupante] do Palácio do Planalto } \\
\cline { 2 - 2 } & presidente sem votos \\
\cline { 2 - 2 } & $\begin{array}{l}\text { impopularidade comparável a de mandatários depostos depois da } \\
\text { redemocratização }\end{array}$ \\
\cline { 2 - 2 } & não conteve investigações de corrupção \\
\hline
\end{tabular}

Fonte: O Autor 
Quadro 2: Como os jornais avaliam seu desempenho

\begin{tabular}{|l|l|}
\hline OESP & conseguiu plantar importantes bases para [...] governabilidade \\
\cline { 2 - 2 } & $\begin{array}{l}\text { vem trabalhando, junto com o Congresso, para reduzir os danos } \\
\text { causados pela irresponsabilidade do lulopetismo [...] foi muito } \\
\text { bem-sucedido }\end{array}$ \\
\cline { 2 - 2 } & $\begin{array}{l}\text { a desigualdade social -contra a qual o governo petista dizia lutar- } \\
\text { parou de cair }\end{array}$ \\
\hline \multirow{2}{*}{ FSP } & conseguiu estancar degradação dramática da economia \\
\cline { 2 - 2 } & rombo [contas públicas] foi contido; inflação em queda \\
\cline { 2 - 2 } & afora a economia, é medíocre [na maior parte dos ministérios] \\
\cline { 2 - 2 } & predomina um conservadorismo arcaico \\
\cline { 2 - 2 } & tem cumprido tarefas centrais \\
\hline
\end{tabular}

Fonte: O Autor

Quadro 3: O que os jornais consideram sua principal missão

\begin{tabular}{|l|l|}
\hline OESP & $\begin{array}{l}\text { avançar reformas fundamentais [trabalhista e previdenciária] sem } \\
\text { as quais a recuperação da economia é simplesmente impossível. }\end{array}$ \\
\hline FSP & [sua agenda] provocará transformações profundas \\
\cline { 2 - 2 } & $\begin{array}{l}\text { avançam projetos destinados a evitar falência dos Estados e } \\
\text { flexibilizar a CLT }\end{array}$ \\
\hline
\end{tabular}

Fonte: O Autor

Quadro 4: Em nome de quem falam as publicações

\begin{tabular}{|l|l|}
\hline OESP & $\begin{array}{l}\text { diante de reformas naturalmente amargas, parece convencido de } \\
\text { que seu papel é colocar a casa em ordem }\end{array}$ \\
\cline { 2 - 3 } & [realizar reformas] lhe garantirá um lugar de destaque na história \\
\cline { 2 - 2 } & não é um legado qualquer \\
\hline FSP & $\begin{array}{l}\text { sucesso depende de reforma da Previdência [...] para a retomada da } \\
\text { confiança de empresários e investidores }\end{array}$ \\
\cline { 2 - 2 } & $\begin{array}{l}\text { [suas] medidas redesenham as relações de trabalho e seguridade; } \\
\text { restringem a intervenção e o tamanho do Estado }\end{array}$ \\
\cline { 2 - 2 } & $\begin{array}{l}\text { o plano de concessões em infraestrutura [...] mostra pouco } \\
\text { resultado }\end{array}$ \\
\cline { 2 - 2 } & derrota na reforma previdenciária colocará muito a perder \\
\hline
\end{tabular}

Fonte: O Autor 


\section{midiäticales}

Tendo em vista que a ACD procura associar a ordem discursiva às questões de injustiça e desigualdade sociais, cabe lembrar que as publicações "de referência" observadas circulam em um dos países mais desiguais do mundo, segundo atesta o Relatório Global de Desenvolvimento Humano de 2016. No conjunto de 143 países pesquisados, o Brasil ocupa a $10^{\mathrm{a}}$ posição no ranking da desigualdade (PNUD; IPEA; FJC, 2017, p. 8). Na América Latina e Caribe, a região considerada mais desigual do mundo, o Brasil fica em quarto lugar, estando em condição menos pior que Guatemala, Honduras e Colômbia. No Brasil, apenas seis pessoas possuem riqueza equivalente à dos 50\% mais pobres (MAIA e GRAJEW, 2017).

Estes números sugerem que, percorrendo-se a linha de raciocínio de Luhmann, caberia ao sistema de comunicação, enquanto "operador central de todos os sistemas sociais", tocar na ferida da desigualdade ao avaliar a gestão governamental. De forma mais consequente, equivaleria a articular os atores sociais em torno do bem comum, ou seja, da construção de uma sociedade menos desigual. Caso contrário, podemos entender que os discursos do sistema de mídia podem ser considerados "manipuladores", como sustenta Van Djik, pois implicam em "abuso de poder", com o não enfrentamento de uma situação de flagrante injustiça social.

Os excertos agrupados apontam que, para o jornal OESP, embora "muito malvisto pela opinião pública", Temer possui habilidades para aprovar "urgentes" mudanças na Constituição Brasileira. No editorial da FSP, o único momento em que o jornal lhe reconhece a condição de mandatário é para afirmar que se trata de um "presidente sem votos". Para ambos os jornais, no entanto, conforme atesta o quadro 2 , Temer possui méritos ao conduzir a economia, já tendo "cumprido tarefas centrais" que se esperam dele, uma vez que conseguiu "estancar a degradação dramática das contas públicas”. Essa degradação teria ocorrido -segundo o $O E S P$ - em função do "lulopetismo", expressão que designa a corrente majoritária do Partido dos Trabalhadores (PT), que governou o país entre 2003 e 2016.

$\mathrm{O}$ quadro 3 indica que o principal desafio de Temer à frente do cargo será implantar "reformas fundamentais", como a trabalhista e a previdenciária, "sem as quais a recuperação da economia é simplesmente impossível". A FSP é mais enfática ao prever (positivamente) que a flexibilização da Consolidação das Leis do Trabalho (CLT) provocará transformações profundas na relação capital/trabalho. 


\section{midiäticales}

O quadro 4 sinaliza quem são os enunciadores dos discursos circulados: "colocar a casa em ordem", adotando "reformas naturalmente amargas" (OESP), implica na "retomada da confiança de empresários e investidores" (FSP). Em outros termos, é preciso tornar o Brasil atraente aos interesses do capital, mesmo que isto implique na perda de direitos sociais. Registre-se que, dos dois jornais, o único a mencionar a necessidade de reduzir desigualdades foi $O$ Estado de S. Paulo.

Embora menor, o editorial da FSP melhor detalhou o que é esperado (pelos enunciadores) do "presidente sem votos": reformas trabalhista e previdenciária (reduzindo-se direitos dos trabalhadores e dos aposentados); desregulamentação dos contratos sociais e redução do tamanho do Estado. Retomando Van Djik (2005, p. 15), no momento em que "os membros de um grupo explicam, motivam ou legitimam suas ações (grupais), o fazem tipicamente em termos de discurso ideológico”. As marcas discursivas ali presentes, de alteração da legislação trabalhista, do fim das garantias sociais, da redução do papel do Estado e do oferecimento de melhores condições para investidores (cujo objetivo é sempre obter melhores remunerações para o capital) pertencem ao ideário neoliberal.

Ao que se deduz, pouco importa, para os enunciadores (os jornais) a legitimidade ou popularidade do mandatário, desde que no exercício do cargo ele tome medidas consideradas adequadas para que o país se adapte a um sistema que hoje se apresenta como única opção. Sistema esse que -como já apontou Milton Santos (2001, p. 60)- “inclui a morte da política (com P maiúsculo), já que a condução do processo político passa a ser atributo das grandes empresas."

Anteriormente, introduzimos a expressão enunciador como referência à instituição jornal, o que nos leva à noção de coenunciador de ambos os editoriais. Seria este o próprio poder econômico - em nome de quem falam as publicações. Poder econômico que, como diz Bauman (2001), produziu uma experiência até então não vivenciada pelo mundo desenvolvido, que hoje combina a falta de garantias à incerteza e à insegurança. Sua origem seria basicamente a precarização das condições de vida em um universo sem trabalho ou emprego, no qual a ordem do dia nos remete à palavra "flexibilidade" para as relações de trabalho. Trata-se esta de uma expressão que "anuncia empregos sem segurança, compromissos ou direitos, que oferecem apenas 


\section{midiäticales}

contratos a prazo fixo ou renováveis, demissão sem aviso prévio e nenhum direito à compensação" (BAUMAN, 2001, p. 185).

O campo da linguística também nos fornece a noção de coenunciatários - a quem se dirigem os editoriais e endossam dos valores ali expressos. Referimo-nos à parcela da sociedade cujos interesses estão preservados ou acriticamente representados na doutrina neoliberal, uma quase seita na atual etapa do capitalismo globalizante. Ao descrevê-la, o autor de Modernidade líquida se refere a "uma população dócil, incapaz ou não desejosa de oferecer resistência organizada a qualquer decisão que o capital venha a tomar" (BAUMAN, 2001, p. 173).

Para que se completem os passos propostos pela ACD, é preciso observar que os jornais mencionados também fizeram circular, em textos opinativos de alguns de seus colaboradores, discursos contrários ao que prescreveram seus editoriais. Um bom exemplo foi a charge do cartunista Laerte, publicada em 11 de julho na página 2 da Folha de S. Paulo. No desenho, vê-se uma galé tocada por remadores esgotados (incluindo uma mulher com criança de colo); na proa, sob uma corrente de ar, um sujeito sorridente e engravatado ouve de outro engravatado: "Ah!... a brisa da modernidade trabalhista".

À crítica do cartunista, somaram-se, ao lado de matérias e artigos favoráveis às reformas, outros textos que condenavam e denunciavam a ilegitimidade de seu proponente. A estratégia nos leva mais uma vez a concordar com Fairclough (2012b, p. 316): "a colonização nunca é um processo simples". Em outros termos, a existência da hegemonia não descarta a luta de contrapoder (VAN DJIK, 2005, p. 27).

No quarto dos cinco passos propostos pela $\mathrm{ACD}$, entendemos que, antes de saírem na defesa dos ideais representados pelo "presidente sem voto", caberia aos jornais melhor zelar pelos pressupostos da democracia. Aprovar mudanças em parceria com um Congresso eleito com recursos oriundos do poder econômico, contra o qual pesam denúncias de corrupção, não resolve o problema de sua ilegitimidade. Uma saída ao impasse, que os editoriais poderiam ter cogitado, seria aguardar-se que a sociedade brasileira, nas eleições seguintes, tivesse alguma chance de participar do debate. 


\section{midiática@e}

\section{Considerações finais}

Reservamos para esta etapa do trabalho o quinto e último passo da abordagem preconizada pala ACD. Trata-se de elaborar uma reflexão crítica acerca da própria análise, o que nos leva a pelo menos três observações importantes. A primeira diz respeito à impossibilidade de fazer generalizações, uma vez que o percurso adotado refere-se a um universo pequeno, embora significativo, da realidade brasileira. O país possui um certo contingente de jornais e demais publicações que não acolhem o neoliberalismo em suas linhas editoriais. Recentemente, por exemplo, passou a contar com uma versão nacional digital do diário espanhol El País, publicação que se destaca entre os chamados "jornais de referência" e que tem atuado como um fiel da balança na cacofonia em que se transformou a internet em situações de polarização como a aqui estudada.

Em segundo lugar, até por conta do limite de espaço, não tocamos um tema que tem preocupado importantes atores sociais das duas vertentes que hoje se antagonizam no país: o crescimento do populismo na América Latina. Trata-se de uma região que, historicamente, reúne condições favoráveis ao surgimento de "salvadores da pátria", "pais dos pobres" ou "caçadores de marajás". Uma vez no poder, eles dificilmente se preocupam com a emancipação de seus povos, pois estão sempre voltados a se reeleger para manter privilégios corporativos. Em larga medida, este receio explica o apoio dos "jornais de referência" ao "presidente sem votos".

Por fim, cabe registrar que o percurso trilhado, se não nos deu plena garantia para a apreensão do problema, ao menos nos assegurou o mínimo de subjetividade no percurso analítico. A criação dos quadros temáticos, embora não esteja no protocolo da ACD, mostrou-se de grande ajuda para organizar, entender e entrecruzar discursos acerca de um mesmo objeto: o controle que as elites simbólicas exercem sobre a produção discursiva. A politização do olhar, tendo por referência o reconhecido domínio hegemônico neoliberal, pode ser considerada uma importante contribuição que trabalhos desta natureza podem trazer às ciências sociais. 


\section{midiäticajege}

\section{Referências}

BAUMAN, Zygmunt. Modernidade líquida. Rio de Janeiro: Zahar, 2001.

BILENKY, Thaís. Aprovação de Temer cai a 7\%, menor em 28 anos, diz Datafolha.

Folha Digital. Poder. Publicado em 24 Jun. 2017. Disponível em:

$<$ http://www1.folha.uol.com.br/poder/2017/06/1895645-aprovacao-da-gestao-temercai-a-7-menor-em-28-anos.shtml>. Acesso em: 15 Jul. 2017.

BRASIL. Presidência da República. Secretaria de Comunicação Social

(Secom). Pesquisa brasileira de mídia 2016. Brasília, 2016. 162 p. Empresa responsável: Ibope Inteligência.

CHAPARRO, Manuel Carlos. Jornalismo linguagem dos conflitos. São Paulo: Edição do Autor, 2014.

FAIRCLOUGH, Norman. Critical discourse analysis. In: GEE, James Paul; HANDFORD, Michael. The routledge handbook of discourse analysis. New York: Routledge, 2012a, p. 9-20.

Análise crítica do discurso como método em pesquisa social científica. Linha D'Água, São Paulo, v. 2, n. 25, p.307-329, 2012b. Semestral. Tradução de: Iran Ferreira de Melo. Disponível em:

$<$ http://www.revistas.usp.br/linhadagua/article/view/47728/51460>. Acesso em: 5 Abr. 2016.

FOLHA DE S. PAULO. Novo manual da redação. São Paulo, 1992.

FOUCAULT, Michel. Microfísica do poder. Rio de Janeiro: Graal, 1979.

KUSHNIR, Beatriz. A grande imprensa apoiou o golpe e a ditadura. Cartacapital. Especial 50 anos do golpe. Publicado em: 31 mar 2014. Acesso em: 20 Abr. 2015. Disponível em: <https://www.cartacapital.com.br/politica/a-grande-impressa-apoiou-ogolpe-e-a-ditadura-e-nao-teve-papel-relevante-para-o-fim-do-regime-1979.html> . Acesso em: 5 Abr. 2016.

LUHMANN, Niklás. A realidade dos meios de comunicação. São Paulo: Paulus, 2005. (Comunicação). Tradução de: Ciro Marcondes Filho.

MAIA, Kátia; GRAJEW, Oded. A reforma da Previdência e as desigualdades. Folha de S. Paulo. Opinião. São Paulo, 15 Jun. 2017, p. A3.

MARCONDES FILHO, Ciro. Prefácio à edição brasileira. In: LUHMANN, Niklás. A realidade dos meios de comunicação. São Paulo: Paulus, 2005, pp. 7-12. 


\section{midiätica@s}

MELO, José Marques de. A opinião no jornalismo brasileiro. 2. ed. Petrópolis, Rj: Vozes, 1994. (Comunicação de massa).

Jornalismo opinativo: gêneros opinativos no jornalismo brasileiro. 3. ed.

Campos do Jordão: Mantiqueira, 2003.

MEYER, Philip. Os jornais podem desaparecer? como salvar o jornalismo na era da informação. São Paulo: Contexto, 2007.

MOURA, João Benvindo de. Análise discursiva de editoriais do jornal Meio Norte, do Estado do Piauí: A construção de imagens e as emoções suscitáveis através da argumentação. 2012. 271 f. Tese (Doutorado) - Curso de Faculdade de Letras, Universidade Federal de Minas Gerais, Belo Horizonte, 2012.

MÜLLER, Carlos Alves. A crise estrutural dos jornais: uma exploração comparativa sobre a situação nos EUA e no Brasil. Revista de Estudos e Pesquisas Sobre As Américas, Brasília, v. 5, n. 1, p. 80-108, 2011. Disponível em: <http://periodicos.unb.br/index.php/repam/article/view/5580/4661>. Acesso em: 10 Jun. 14.

O BALANÇO de Temer. Folha de S. Paulo, São Paulo, p. 2, 14 Mai. 2017. Disponível em: http://www1.folha.uol.com.br/opiniao/2017/05/1883816-o-balanco-de-temer.shtml. Acesso em: 20 Jun. 2017.

PNUD; IPEA, FJC. Desenvolvimento humano para além das médias: 2017. Brasília, 2017, 127 p.

RESENDE, Viviane de Melo; RAMALHO, Viviane. Análise do discurso crítica. 2. ed. São Paulo: Contexto, 2014.

SACCHITIELLO, Bárbara. Meio \& Mensagem: Cai circulação dos grandes jornais. 2016. Disponível em:

<http://www.meioemensagem.com.br/home/midia/2016/08/08/cai-a-circulacao-dosgrandes-jornais.html>. Acesso em: 8 Ago. 2016.

SANTOS, Milton. Por uma outra globalização: Do pensamento único à consciência universal. 5. ed. Rio de Janeiro: Record, 2001. 263 p.

SERRANO, Estrela. Jornalismo e elites do poder. Ciberlegenda, Universidade Federal Fluminense, p.1-18, 1999. Disponível em:

<http://www.ciberlegenda.uff.br/index.php/revista/article/viewFile/272/157>. Acesso em: 20 Mai. 2017.

SILVERSTONE, Roger. Por que estudar a mídia? São Paulo: Edições Loyola, 2002.

SILVA, Marconi Oliveira da. A notícia como narrativa e discurso. Estudos em Jornalismo e Mídia, Florianópolis, v. 1, n. 4, p. 49-64, 2007. Semestral. Disponível 


\section{midiätica@e}

em: <https://periodicos.ufsc.br/index.php/jornalismo/article/view/2200/2053>. Acesso em: 20 Mai. 2017.

SILVA, Maria da Graça Bernardes e. O tempo dos horários-limites (deadlines) nos jornais Folha de S. Paulo e O Estado de S. Paulo. In: ENCONTRO DOS NÚCLEOS DE PESQUISA DA INTERCOM, 4, 2004, Porto Alegre. Anais do IV Encontro dos Núcleos de Pesquisa da Intercom. Porto Alegre: Intercom, 2004. p. 1- 9. Disponível em: <http://www.ccmj.org.br/sites/default/files/SILVA Maria da Graca Bernardes e.pdf>. Acesso em: 10 Fev. 2008.

THOMPSON, John B.. A mídia e a modernidade: uma teoria da comunicação linear e em rede. 5. ed. Petrópolis, Rj: Vozes, 1998.

UM ANO do governo Temer. O Estado de S. Paulo, São Paulo, p. 3, 12 Mai 2017. Disponível em: <http://opiniao.estadao.com.br/noticias/geral,um-ano-do-governotemer,70001775279>. Acesso em: 20 Jun. 2017.

VAN DJIK, Teun; HOFFNAGEL, Judith; FALCONE, Karina (Org.). Discurso e poder. 2. ed. São Paulo: Contexto, 2015.

. Ideología y análisis del discurso. Estudio: Utopía y práxis

latinoamericana, Maracaibo, v. 29, p. 9-36, 2005.

WANG, Jiayu. A new political and communication agenda for political discourse analysis: Critical reflections on critical discourse analysis and political discourse analysis. International Journal Of Communication, Los Angeles (EUA), n. 10, p. 2766-2784, 2016. Disponível em:

<http://ijoc.org/index.php/ijoc/article/view/3847/1679>. Acesso em: 8 Mar. 2017.

ZAMIN, Ângela. Jornalismo de referência: o conceito por trás da expressão. Revista Famecos: mídia, cultura e tecnologia, Porto Alegre, v. 21, n. 3, p. 918-942, 2014. Disponível em: $<$ http://revistaseletronicas.pucrs.br/ojs/index.php/revistafamecos/article/view/16716/125 70>. Acesso em: 06 Mar. 2015.

ZANOTTI, Carlos A. Jornal: continente e conteúdo. Correio Popular. Campinas, 21 Jul. 2016, p. A2. 